\title{
Determination of in situ ruminal degradation of phytate phosphorus from single and compound feeds in dairy cows using chemical analysis and near-infrared spectroscopy
}

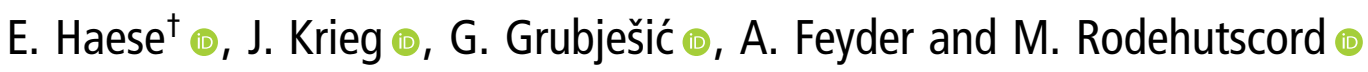 \\ Institut für Nutztierwissenschaften, Universität Hohenheim, Emil-Wolff-Str. 6-10, 70599 Stuttgart, Germany
}

(Received 22 September 2019; Accepted 30 January 2020; First published online 5 March 2020)

\begin{abstract}
The ruminal degradation of $P$ bound in phytate (Ins $P_{6}$ ) can vary between feeds, but data on ruminal degradation of Ins $P_{6}$ from different feedstuffs for cattle are rare. One objective of this study was to increase the data base on ruminal effective degradation of InsP $P_{6}$ (Ins $P_{6} E D$ ) and to assess if Ins $P_{6} E D$ of compound feeds (CF) can be calculated from comprising single feeds. As a second objective, use of near-infrared spectroscopy (NIRS) to predict Ins $P_{6}$ concentrations was tested. Nine single feeds (maize, wheat, barley, faba beans, soybeans, soybean meal (SBM), rapeseed meal (RSM), sunflower meal (SFM), dried distillers' grains with solubles (DDGS)) and two CF (CF1/CF2), consisting of different amounts of the examined single feeds, were incubated for 2, 4, $8,16,24,48$ and $72 \mathrm{~h}$ in the rumen of three ruminally fistulated Jersey cows. Samples of CF were examined before (CF1/CF2 Mash) and after pelleting (CF1/CF2 Pellet), and Ins $P_{6} E D$ was calculated for all feeds at two passage rates (Ins $P_{6} E D_{5}: \mathrm{k}=5 \% / h$; Ins $\left.P_{6} E D_{8}: \mathrm{k}=8 \% / h\right)$. For $C F 1$ and $C F 2$, Ins $P_{6} E D$ was also calculated from values of the respective single feeds. Near-infrared spectra were recorded in duplicate and used to establish calibrations to predict Ins $P_{6}$ concentration. Besides a global calibration, also local calibrations were evaluated by separating samples into different data sets based on their origin. The Ins $P_{6} E D_{8}$ was highest for faba beans (91\%), followed by maize (90\%), DDGS (89\%), soybeans (85\%), wheat (76\%) and barley (74\%). Lower values were determined for oilseed meals (48\% RSM, 65\% SFM, 66\% SBM). Calculating Ins $P_{6} E D$ of CF from values of single feeds underestimated observed values up to 11 percentage points. The NIRS calibrations in general showed a good performance, but statistical key data suggest that local calibrations should be established. The wide variation of Ins $P_{6} E D$ between feeds indicates that the ruminal availability of $P$ bound in $I n s P_{6}$ should be evaluated individually for feeds. This requires further in situ studies with high amounts of samples for $\operatorname{Ins}_{6}$ analysis. Near-infrared spectroscopy has the potential to simplify the analytical step of $I n s P_{6}$ in the future, but the calibrations need to be expanded.
\end{abstract}

Keywords: feed evaluation, phosphorus availability, phytate degradation, rumen, analytical method

\section{Implications}

Phosphorus is essential for health, milk production and reproduction of dairy cows but contributes to environmental pollution when excreted. In plant seeds, $\mathrm{P}$ is mainly stored as phytate, but phytate degradation and, thus, availability of $P$ in the rumen vary widely between different feeds. Data on ruminal phytate degradation of feeds commonly fed to dairy cows improves diet calculations contributing to an adequate $P$ supply of the animals. In the future, the data base on ruminal phytate degradation can be further increased when near-infrared spectroscopy is used to predict phytate concentrations instead of elaborate chemical analysis.

\footnotetext{
† E-mail: inst450@uni-hohenheim.de
}

\section{Introduction}

An adequate supply of $P$ is essential to ensure health and performance of dairy cows. However, faecal $P$ excretion increases with $\mathrm{P}$ intake in a linear manner (Wu et al., 2001), and P concentrations in the diet exceeding the animals' requirement lead to increased faecal P excretion. Phosphorus losses can contribute to eutrophication of natural waters (Desmit et al., 2018) and, thus, excessive P supply in animal nutrition has to be avoided.

In plant seeds and by-products, $\mathrm{P}$ is contained predominantly as phytate (any salt of phytic acid; myo-inositol 1,2,3,4,5,6-hexakis (dihydrogen phosphate); Ins $\mathbf{P}_{6}$ ). Rumen microorganisms show substantial phytase activity (Yanke et al., 1998) which enables the hydrolytic cleavage of 
$\mathrm{P}$ bound in $\operatorname{Ins}_{6}\left(\operatorname{Ins}_{6}-\mathrm{P}\right)$ and subsequent $\mathrm{P}$ absorption in the intestine. However, results of studies examining total tract disappearance of $\operatorname{Ins}_{6}$ are inconsistent. While several studies found only low faecal Ins $\mathrm{P}_{6}$ excretion of about $5 \%$ of ingested InsP $_{6}$ (e.g. Morse et al., 1992; Ray et al., 2013), others reported higher proportions of $\operatorname{InsP}_{6}$ excreted (e.g. Haese et al., 2014: up to $15 \%$; Kincaid et al., 2005: more than $20 \%$ of ingested InsP $\mathrm{P}_{6}$ ). Some of the observed differences can likely be explained by the wide variation of feed ingredients used in the diets. Earlier in vitro and in situ studies have shown that progression and extent of ruminal $\operatorname{Ins}_{6}$ disappearance differ between feedstuffs. In rapeseed meal (RSM), InsP ${ }_{6}$ disappearance proceeded slowly compared to maize (Haese et al., 2017a), soybean meal (SBM) and wheat (Haese et al., 2017b), leading to a lower effective $\operatorname{Ins}_{6}$ degradation of RSM in the rumen compared to SBM (Park et al., 1999). However, data on effective degradation of $\operatorname{InsP}_{6}\left(\right.$ Ins $_{6}$ ED) in common feeds for cattle are rare to date. Thus, the first objective of the present study was to determine InsP $\mathrm{P}_{6} \mathrm{ED}$ from different single feeds used in cattle feeding. Furthermore, we determined Ins $\mathrm{P}_{6}$ ED of compound feeds (CF) to assess if InsP $\mathrm{P}_{6}$ degradation values from single feeds are additive in CF. This would allow for calculations of InsP $\mathrm{P}_{6} \mathrm{ED}$ for any compound feed if respective values are given for the utilised single feeds. Increased data on the ruminal availability of $\operatorname{Ins}_{6}-\mathrm{P}$ from different feeds may allow for more precise calculation of dietary $P$ supply of dairy cows in the future.

In situ studies to determine Ins $\mathrm{P}_{6} \mathrm{ED}$ provide a large number of samples to be analysed for inositol phosphates (InsPs). Most commonly, high-performance ion chromatography (HPIC) with gradient elution or similar chromatography is used to separate InsPs and their isomers in feeds (Blaabjerg et al., 2010). However, this technique is laborious and costly and is not established as a routine method for common feed analysis. Hence, faster and easier methods for analysis of Ins $\mathrm{P}_{6}$ would be beneficial to increase the data base of ruminal $\operatorname{Ins}_{6}$ degradation of feeds. Various studies showed that near-infrared spectroscopy (NIRS) can be used to predict the concentration of InsP $_{6}$ (Zhao et al., 2017) and InsP $\mathrm{P}_{6}-\mathrm{P}$ (Tahir et al., 2012; Aureli et al., 2017), while studies that applied this technique to in situ samples were not reported. However, for cereal grains, NIRS has been successfully used to predict CP and starch in bag residues after ruminal incubation (Krieg et al., 2018a). Hence, the second objective of this study was to establish calibrations to predict the $\operatorname{Ins}_{6}$ concentration of feeds and ruminally incubated bag residues using NIRS. In order to examine the suitability of NIRS estimations for the usage in in situ studies, $\operatorname{InsP}_{6} \mathrm{ED}_{\text {calculated from NIRS-derived InsP }}$ concentrations was compared to those calculated from chemically analysed $\mathrm{InSP}_{6}$ concentrations of the samples.

\section{Material and methods}

\section{Samples and incubations}

Samples of single and compound feeds and their respective bag residues originated from an in situ study described in detail by Grubješić et al. (2019). Nine single feeds (maize, wheat, barley, faba beans, soybeans, SBM, RSM, sunflower meal (SFM), dried distillers' grains with solubles (DDGS)) and two CF (CF1, CF2) composed of different amounts of these single feeds were used for analysis of InsPs. Compound feed 1 consisted of $10 \%$ maize, $46 \%$ barley, $16 \%$ faba beans, $18 \%$ soybeans, $5 \%$ SBM and $5 \%$ DDGS, while CF2 contained $32 \%$ maize, $12 \%$ wheat, $16 \%$ faba beans, $8 \%$ SBM, 17\% RSM, 10\% SFM and 5\% DDGS (values on DM basis). The CF were produced in a commercial feed mill as described in detail by Grubješić et al. (2019). In brief, single feeds were ground through a $3 \mathrm{~mm}$ sieve and mixed into the CF. Subsequently, one portion of the compound feed was pelleted at $50^{\circ} \mathrm{C}$ to $60^{\circ} \mathrm{C}$ (exit temperature $80^{\circ} \mathrm{C}$ to $90^{\circ} \mathrm{C}$ ). For the in situ incubations of CF1 and CF2, samples were taken before (Mash) and after pelleting (Pellet).

The ruminal incubation followed the procedure of Seifried et al. (2017) and was also described in detail by Grubješic et al. (2019). In brief, feed samples were ground to pass a $2 \mathrm{~mm}$ sieve and $8 \mathrm{~g}$ were weighed into polyester bags $(10 \times 20 \mathrm{~cm}$, pore size $50 \mu \mathrm{m}$, ANKOM Technology, USA) with 3 to 5 replicates per sample, incubation time and animal. The bags were incubated in the rumen of three rumen-fistulated Jersey cows for $2,4,8,16,24,48$ and $72 \mathrm{~h}$ and washed in a washing machine after incubation. Values for incubation time $0 \mathrm{~h}$ were gained by washing three replicates of each feed sample in the washing machine without ruminal incubation. For analysis, the dried replicates were weighed and pooled per feed sample, incubation time and animal.

\section{Chemical analysis}

Dry matter of feed samples and bag residues was analysed according to the official methods used in Germany (Verband Deutscher Landwirtschaftlicher Untersuchungsund Forschungsanstalten, 2007). Analysis of $\operatorname{InsP}_{6}$ and isomers of lower InsPs (myo-inositol pentakisphosphate $\left(\right.$ InsP $\left._{5}\right)$, myo-inositol tetrakisphosphate (InsP $\mathrm{P}_{4}$ ) and myoinositol trisphosphate (Ins: $\left.\mathrm{P}_{3}\right)$ ) was performed as described by Zeller et al. (2015) with slight modifications regarding sample size and agent used for extraction. In brief, $0.1 \mathrm{~g}$ of the sample was extracted for $30 \mathrm{~min}$ with $1.0 \mathrm{ml}$ of an extracting agent $(0.2 \mathrm{Mol}$ ethylenediaminetetraacetate and $0.1 \mathrm{Mol} \mathrm{NaF}$, pH 8.0) on a rotary shaker. After centrifugation, the supernatant was removed, preserved on ice and the residue re-suspended with $0.5 \mathrm{ml}$ extracting agent and extracted again for $30 \mathrm{~min}$. The supernatants of both extraction steps were merged, filtered and centrifuged. Filtrates were analysed by HPIC (ICS-3000, Fa. Dionex, Idstein, Germany) and UV detection at $290 \mathrm{~nm}$.

\section{Calculations}

For each feed, degradation parameters $\boldsymbol{a}(\%$; rapidly disappearing fraction), $\boldsymbol{b}(\%$; potentially degradable fraction), $\boldsymbol{a}+\boldsymbol{b}$ $(\%$; maximum degradation/plateau) and $\boldsymbol{c}(\% / \mathrm{h}$; degradation rate) of $\mathrm{InSP}_{6}$ were calculated based on HPIC-derived 
Ins $\mathrm{P}_{6}$ concentrations using the equations described by Orskov and McDonald (1979) (equation (1)) and McDonald (1981) (equation (2)).

$$
\begin{gathered}
\operatorname{Deg}=a+b \times\left(1-e^{-c \mathrm{t}}\right) \\
\operatorname{Deg}=a+b \times\left(1-e^{-c(\mathrm{t}-\mathrm{L})}\right) \quad \text { for } t>\mathrm{L}
\end{gathered}
$$

where Deg (\%) is the ruminal degradation of Ins $_{6}$ after $t h$ and $\mathrm{L}$ represents lag time. Using the GraphPad Prism software (Version 5.0 for Windows, GraphPad Software, CA, USA), the best fitting model for each feed was selected based on the Akaike Information Criterion. For estimation of degradation values, estimations of fraction $a$ and fraction $a+b$ were constrained to 0 and $100 \%$, respectively. The degradation parameters of $\mathrm{InsP}_{6}$ were then used to calculate the Ins $\mathrm{P}_{6} \mathrm{ED}$ at ruminal outflow rates of $k=5\left(\operatorname{Ins}_{6} \mathrm{ED}_{5}\right)$ or 8 $\left(\right.$ Ins $\left.\mathrm{P}_{6} \mathrm{ED}_{8}\right) \% / \mathrm{h}$ with either

$$
\operatorname{Ins} \mathrm{P}_{6} \mathrm{ED}=a+[(b \times c) /(c+k)]
$$

according to Orskov and McDonald (1979) or

$$
\operatorname{InsP}_{6} \mathrm{ED}=a+[(b \times c) /(c+k)] e^{-k \mathrm{~L}}
$$

according to Wulf and Südekum (2005).

For the $C F$, the degradation parameters and Ins $\mathrm{P}_{6} \mathrm{ED}$ values were additionally calculated from the observed values of single feeds as described by Grubješić et al. (2019) using

$$
\begin{aligned}
\mathrm{dCF}_{(1,2)} \mathrm{Calc}= & {\left[\left(\mathrm{dSF}_{1} \times w_{1}\right)+\left(\mathrm{dSF}_{2} \times w_{2}\right)+\cdots\right.} \\
& \left.+\left(\mathrm{dSF}_{i} \times w_{i}\right)\right] / 100
\end{aligned}
$$

$\mathrm{dCF}_{(1,2)} \mathrm{calc}=$ calculated degradation characteristics $(a, b, c$, lag, Ins $\mathrm{P}_{6} \mathrm{ED}_{5}, \mathrm{InSP}_{6} \mathrm{ED}_{8}$ ) of $\mathrm{CF} 1$ or $\mathrm{CF} 2$

$\mathrm{dSF}_{i}=$ observed degradation characteristics $\left(a, b\right.$, $c$ lag, $\operatorname{Ins}_{6} \mathrm{ED}_{5}$, InsP ${ }_{6} \mathrm{ED}_{8}$ ) of single feed $i$

$w_{i}=$ weighted Ins $\mathrm{P}_{6}$ contribution of single feed $i$ to total $\operatorname{Ins}_{6}$ pool of CF1 or CF2

Degradation parameters and $\operatorname{Ins}_{6} \mathrm{ED}$ were calculated for each cow separately, using cow as experimental unit in statistical analysis.

\section{Near-infrared spectroscopy}

Because the number of feeds used in this study was relatively low for developing NIRS calibrations for InsP ${ }_{6}$, values of samples from earlier in situ studies were added to the data pool. All additional data originated from studies where different feeds were ruminally incubated and analysed for $\operatorname{Ins}_{6}$ concentrations using HPIC as described before. The additional data included values for barley, maize, rye, triticale and wheat (Seifried et al., 2016 and 2017; Krieg et al., 2017) and four RSM samples (Haese et al., 2017c). Different combinations of samples were tested for the establishment of calibrations in order to compare the performance of local calibrations (including only one type of feed, e.g. cereal grains) with global calibrations (including all feed types) and to achieve the overall best performance. $A$ total of seven data sets was created using different combinations of feeds and corresponding bag residues:

Data set 1: all values for feeds and bag residues of the present study Data set 2: all values for feeds and bag residues of the present study and the additional studies (Seifried et al., 2016 and 2017; Haese et al., 2017c; Krieg et al., 2017)

Data set 3: data set 2, but excluding all values for rye and triticale Data set 4: only values for feeds and bag residues from grain samples of the present study and the additional studies

Data set 5: data set 2, but excluding all values for grain samples Data set 6: data set 2, but excluding all values for CF

Data set 7: data set 2, but excluding all values for CF and grain samples.

Number of samples used for calibration and validation data sets are shown in Table 1.

Spectra were recorded in duplicate from 680 to $2500 \mathrm{~nm}$ (SpectraStar 2500X, Software: Unity InfoStar Version 3.11.1, Unity Scientific, Brookfield, CT). Additionally, spectra of an internal standard as well as external standards (US-STDS0001 - STD, Wavelength cert, R99 and US-STDS-0003 - STD, Wavelength cert, R99/Poly; Unity Scientific, Brookfield, CT) were recorded throughout the measurements. Mathematical treatment of the spectra and calibrations computation were carried out using the software Ucalibrate (Version: 3.0.0.23; Unity Scientific, Brookfield, CT). The spectra were averaged per sample, and the averaged spectrum of each sample was mathematically pre-treated by standard normal variates

Table 1 Number (n) of feed samples used for calibration development and validation. Mean and range of chemically analysed phytate (InsP $\left.P_{6}\right)$ concentration of feeds and bag residues after in situ incubation '

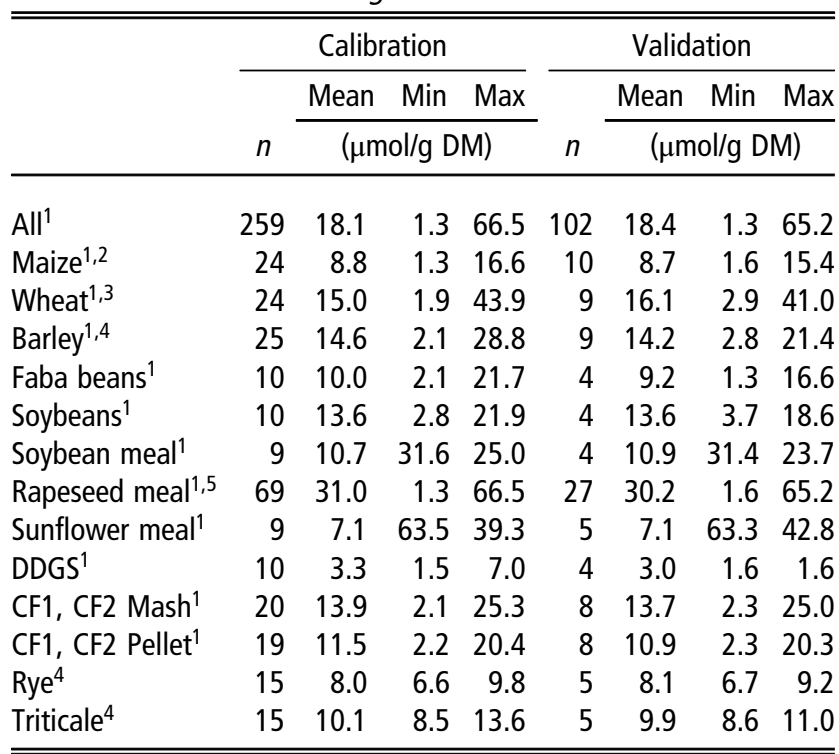

Min = minimum value; Max = maximum value.

Samples of ${ }^{1}$ the present study, ${ }^{2}$ Seifried et al. (2016) ${ }^{3}$ Seifried et al. (2017) ${ }^{4}$ Krieg et al. (2017), ${ }^{5}$ Haese et al. (2017c).

DDGS = dried distillers' grains with solubles; $\mathrm{CF} 1=$ compound feed 1 (containing $10 \%$ maize, $46 \%$ barley, $16 \%$ faba beans, $18 \%$ soybeans, $5 \%$ soybean meal, $5 \%$ DDGS on DM basis); CF2 = compound feed 2 (containing $32 \%$ maize, $12 \%$ wheat, $16 \%$ faba beans, $8 \%$ soybean meal, $17 \%$ rapeseed meal, $10 \%$ sunflower meal, $5 \%$ DDGS on DM basis). 
and detrending. Derivations of the spectra were computed using a derivation gap and smoothing steps of eight. The derivation option varied between no derivation and first- or second-order derivation. Subsequently, the spectra were used for calibration calculation. The samples were split into a calibration and a validation set for each feed type as outlined in Table 1, attempting to include the whole range of $\operatorname{InsP}_{6}$ concentrations in both calibration and validation sets.

Three wavelength segments were compared: (1) the complete recorded spectrum $(680-2500 \mathrm{~nm}),(2)$ the recorded spectrum constricted for $50 \mathrm{~nm}$ from the beginning and the end (730 to $2450 \mathrm{~nm}$ ) and (3) the segment of 1250 to $2450 \mathrm{~nm}$. Segment 2 was used to eliminate possible drifts near the limit of the detection. Segment 3 was used because most $\mathrm{N}-\mathrm{H}$ and $\mathrm{C}-\mathrm{H}$ bonds are known to be located in this area and because the protein and $\operatorname{Ins}_{6}$ concentration correlated in RSM and SBM after ruminal in situ incubation (Haese et al., 2017b). Each of the three wavelength segments was combined with each derivation, resulting in nine calibrations per data set. Stepwise forward partial least squares (PLS)regression was used to compute calibrations. Number of groups for cross validation (CV) varied, depending on the number of samples in the calibrations. The T-limit for outlier detection was set to 2.5 (predicted $v$. reference value), and global distance limit was set to 13 .

Calibration evaluation was carried out using the standard error of calibration (SEC) and the standard error of prediction (SEP) as a measure for the accuracy of the calibration (BellonMaurel et al., 2010). Coefficients of determination (predicted $v$. reference) were also considered. The performance of the calibrations was further evaluated using the bias, the intercept and the slope of the validation step. The target values were zero for the bias and the intercept and one for the slope.

To evaluate the suitability of NIRS as alternative method to $\mathrm{HPIC}$ in in situ experiments, Ins $\mathrm{P}_{6} \mathrm{ED}$ was additionally calculated based on NIRS predicted Ins $\mathrm{P}_{6}$ concentrations of the feeds and bag residues according to equations 1 to 4 (InsP ${ }_{6}$ ED NIRS). The InsP $\mathrm{P}_{6}$ concentrations were predicted using the most accurate calibration and data set. These Ins $P_{6} E D$ values were then compared to Ins $P_{6} E D$ values deduced from Ins $\mathrm{P}_{6}$ concentrations measured using HPIC (InsP $\mathrm{P}_{6}$ ED HPIC).

\section{Statistical analysis}

Degradation parameters $a, b, c$ and lag as well as InsP ${ }_{6} E D$ values were statistically analysed with the SAS MIXED procedure (SAS System for Windows, Version 9.4, SAS Institute, Cary, NC, USA). For single feeds, a one-factorial approach with the following model was used:

$$
Y_{i j}=\mu+A_{i}+\mathrm{SF}_{j}+e_{i j}
$$

with $Y_{i j}$ as responsive mean, $\mu$ as overall mean, $A_{i}$ as random effect of animal $(i=1,2,3), \mathrm{SF}_{\mathrm{j}}$ as fixed effect of single feed ( $j=$ maize, wheat, barley, faba beans, soybeans, SBM, RSM, SFM, DDGS) and $e_{i j}$ as residual error.
Compound feeds were analysed in a two-factorial approach with the model:

$$
Y_{i j}=\mu+A_{i}+\mathrm{CF}_{j}+T_{k}+\mathrm{CF}_{j} \mathrm{~T}_{k}+e_{i j k}
$$

where $\mathrm{CF}_{j}$ is the fixed effect of compound feed ( $\left.j=\mathrm{CF} 1, \mathrm{CF} 2\right)$, $T_{k}$ is the fixed effect of type ( $k=$ Mash, Pellet, Calculated), and $\mathrm{CF}_{j} T_{k}$ is the interaction of $\mathrm{CF}_{j}$ and $T_{k}$. Data are presented as least-squares means (LS means) and pooled standard error of the means (pooled SEM).

For comparison of the Ins $\mathrm{P}_{6} \mathrm{ED}$ values based on chemical and NIRS derived Ins $\mathrm{P}_{6}$ concentrations also a two-factorial approach was used:

$$
y_{i, j, k}=\mu+A_{i}+M_{j}+F_{k}+M_{j} F_{k}+e_{i j k}
$$

where $M_{j}$ is the method used to determine $\operatorname{Ins}_{6}$ concentration $\left(j=\right.$ HPIC, NIRS), $F_{k}$ the feed ( $k=$ maize, wheat, barley, faba beans, soybeans, SBM, RSM, SFM, DDGS, CF1 Mash, CF2 Mash, CF1 Pellet, CF2 Pellet), and $\mathrm{M}_{\mathrm{j}} \mathrm{F}_{\mathrm{k}}$ is the interaction of $\mathrm{M}_{\mathrm{j}}$ and $\mathrm{F}_{\mathrm{k}}$.

Statistical significance was declared at $P<0.05$ for all models. Following a significant $F$ value, $t$-tests were performed to show individual significant differences between means.

\section{Results}

\section{Concentrations of inositol phosphates in single and compound feeds}

The concentration of InsP $P_{6}$ varied from $7.0 \mu \mathrm{mol} / \mathrm{g}$ DM $(4.6 \mathrm{~g} / \mathrm{kg} \mathrm{DM})$ to $49.9 \mu \mathrm{mol} / \mathrm{g}$ DM $(32.9 \mathrm{~g} / \mathrm{kg} \mathrm{DM})$ between the examined feeds (Table 2), with the lowest Ins $\mathrm{P}_{6}$ concentrations in DDGS and cereal grains (7.0 to $12.4 \mu \mathrm{mol} / \mathrm{g} \mathrm{DM} ; 4.6$ to $8.2 \mathrm{~g} / \mathrm{kg} \mathrm{DM}$ ) and the highest in RSM and SFM (36.5 and $49.9 \mu \mathrm{mol} / \mathrm{g} \mathrm{DM} ; 24.1$ and $32.9 \mathrm{~g} / \mathrm{kg} \mathrm{DM}$, respectively). The Ins $\mathrm{P}_{6}$ concentrations in CF1 (Mash and Pellet) were considerably lower compared to CF2.

In cereal grains, only traces of InsP $_{5}$ were determined (below limit of quantification, approximately $0,3 \mu \mathrm{mol} / \mathrm{g} \mathrm{DM}$ ). In the other feeds, InsP $P_{5}$ concentrations ranged from $1.5 \mu \mathrm{mol} / \mathrm{g}$ DM to $7.5 \mu \mathrm{mol} / \mathrm{g}$ DM (Table 2). The highest InsP $\mathrm{P}_{5}$ concentrations were determined in RSM and SFM (5.4 and $7.5 \mu \mathrm{mol} / \mathrm{g} \mathrm{DM}$, respectively). Concentrations of InsPs lower than InsP $\mathrm{P}_{5}$ overall were very low and only for DDGS slightly above the quantifica-

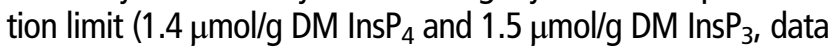
not shown).

\section{Degradation parameters and effective degradation of phytate from single feeds} Ruminal degradation parameters $a, b$ and $c$ differed significantly between the single feeds and ranged from $0 \%$ (RSM) to $77 \%$ (DDGS) for fraction $a$, from $22 \%$ (DDGS) to $100 \%$ (RSM) for fraction $b$ and from $7.3 \% / \mathrm{h}$ (RSM) to $28.2 \% / \mathrm{h}$ (SFM) for degradation rate $c$ (Table 3 ). The $\operatorname{InsP}_{6}$ ED also varied widely between feeds for both calculated passage rates and was highest for faba beans, maize and DDGS (InsP $\mathrm{ED}_{5}$ : 93, 93 and 92\%; InsP $\mathrm{ED}_{8}: 91,90$ and $89 \%$, respectively), 
Table 2 Concentrations of phytate (Ins $\left.P_{6}\right)$ and myo-inositol pentakisphosphate (InsP $\left.P_{5}\right)$ in the examined single and compound feeds ${ }^{1}(\mu \mathrm{mol} / \mathrm{g} \mathrm{DM}$ and $\mathrm{g} / \mathrm{kg} \mathrm{DM})$

\begin{tabular}{lcccc}
\hline \hline & \multicolumn{2}{c}{ InsP $_{6}$} & \multicolumn{2}{c}{ InsP $_{5}$} \\
\hline Feed & $\mu$ mol/g DM & $g / k g ~ D M$ & $\mu$ mol/g DM & $g / k g ~ D M$ \\
Maize & 10.7 & 7.0 & $0.3^{*}$ & $0.2^{*}$ \\
Wheat & 12.4 & 8.2 & $0.3^{*}$ & $0.2^{*}$ \\
Barley & 9.6 & 6.3 & $0.3^{*}$ & $0.2^{*}$ \\
Faba beans & 21.7 & 14.3 & 2.7 & 1.6 \\
Soybeans & 21.8 & 14.4 & 3.9 & 2.2 \\
Soybean & 25.8 & 17.0 & 3.8 & 2.2 \\
$\quad$ meal & & & & \\
Rapeseed & 36.5 & 24.1 & 5.4 & 3.2 \\
$\quad$ meal & & & & \\
Sunflower & 49.9 & 32.9 & 7.5 & 4.4 \\
$\quad$ meal & & & & \\
DDGS & 7.0 & 4.6 & 3.9 & 2.2 \\
CF1 Mash & 13.2 & 8.7 & 2.0 & 1.2 \\
$\quad$ Pellet & 13.5 & 8.9 & 1.5 & 0.9 \\
CF2 Mash & 21.8 & 14.4 & 2.9 & 1.7 \\
$\quad$ Pellet & 19.1 & 12.6 & 2.5 & 1.5 \\
\hline \hline
\end{tabular}

DDGS = dried distillers' grains with solubles; CF1 = compound feed 1 (containing $10 \%$ maize, $46 \%$ barley, $16 \%$ faba beans, $18 \%$ soybeans, $5 \%$ soybean meal, $5 \%$ DDGS on DM basis); CF2 = compound feed 2 (containing $32 \%$ maize, $12 \%$ wheat, $16 \%$ faba beans, $8 \%$ soybean meal, $17 \%$ rapeseed meal, $10 \%$ sunflower meal, $5 \%$ DDGS on DM basis).

*Below limit of quantification, approximate value (mean between limit of detection and limit of quantification).

${ }^{1}$ Chemical composition of the feeds besides inositol phosphates published by Grubješić et al. (2019).

followed by soybeans, wheat and barley ( $\operatorname{InsP}_{6} \mathrm{ED}_{5}: 89,82$, $80 \%$; InsP $\mathrm{ED}_{8}: 85,76,74 \%$, respectively; Table 3). In the oilseed meals, Ins $P_{6} E D$ was lowest with values for $\operatorname{Ins}_{6} \mathrm{ED}_{5}$ and Ins $\mathrm{P}_{6} \mathrm{ED}_{8}$ of 76 and $66 \%$ for $\mathrm{SBM}, 75$ and $65 \%$ for SFM and 59 and $48 \%$ for RSM, respectively. A significant lag time was only calculated for SBM (3.6 h) and SFM (3.1 h).

\section{Degradation parameters and effective degradation of} phytate from compound feeds

In CF, fraction a was significantly higher for both CF Pellets compared to their respective Mash (CF1: 71 v. 56\%, CF2: 56 v. 38\%; Table 4). The same was observed for $\operatorname{InsP}_{6} \mathrm{ED}_{5}$ (CF1:
91 v. $86 \%$, CF2: 85 v $80 \%$ ) and $\operatorname{lnsP}_{6} \mathrm{ED}_{8}$ (CF1: 88 v. $81 \%$, CF2: $80 v$ v. 72\%). For fraction $c$, no interactions between feed and type existed, but the degradation rate was significantly higher for CF2 compared to CF1 (17.5 v. 11.2\%/h). Calculated values for fraction $a_{1} \operatorname{Ins}_{6} \mathrm{ED}_{5}$ and $\operatorname{Ins} \mathrm{P}_{6} \mathrm{ED}_{8}$ did not differ from observed values for CF1 Mash but were lower than the observed values of CF1 Pellet. For CF2, calculated values for fraction $a_{1} \operatorname{InsP}_{6} \mathrm{ED}_{5}$ and $\operatorname{Ins}_{6} \mathrm{ED}_{8}$ were lower than the observed values of CF2 Mash and CF2 Pellet.

\section{Concentrations of lower inositol phosphates after different incubation times}

Isomers of Ins $_{5}$ were detected in the bag residues of all incubated feeds except for maize. Concentrations of $\operatorname{InsP}_{5}$ in the bag residues during the course of incubation are shown in Figure 1. Compared to the concentrations in the feeds, the InsP $_{5}$ concentrations in the bag residues initially increased for wheat, barley, RSM, SFM and CF2 Mash after 2 or $4 \mathrm{~h}$ but decreased quickly afterwards. Only traces of $\operatorname{Ins}_{5}$ were detected in the bag residues after $16 \mathrm{~h}$ (wheat, barley, soybeans, faba beans, DDGS) or $24 \mathrm{~h}$ of incubation (SBM, RSM, SFM, CF1, CF2). Inositol phosphates lower than InsP $\mathrm{P}_{5}$ were only found in the form of $\mathrm{InSP}_{4}$ in the bag residues of SFM (after 2 and $4 \mathrm{~h}$ ) and RSM (after $4 \mathrm{~h}$ of incubation), but the concentrations were negligible (data not shown).

\section{Near-infrared spectroscopy calibrations}

The calibration based on data set 7 showed the highest $R^{2}$ values and the lowest error measurements (Table 5, Figure 2). For all data sets, the first derivation of the spectra showed the best performance. With the exception of data set 4 , the calibration based on the wavelength segment of 1250 to $2450 \mathrm{~nm}$ was chosen for all data sets as the best performing one. Deviation of the prediction from the chemically determined Ins $\mathrm{P}_{6}$ concentration against the predicted value was homogeneously distributed across the whole range of predictions (Figure 2). The $\operatorname{InsP}_{6}$ concentrations of feeds and bag residues derived from data set 7 were then used to calculate $\operatorname{InsP}_{6} \mathrm{ED}$ NIRS for comparison with $\operatorname{InsP}_{6} \mathrm{ED}$ HPIC (Table 6). Significant differences in $\operatorname{Ins}_{6} E D$ values occurred for some feeds. For wheat, barley and CF1 Mash, Ins $\mathrm{P}_{6} \mathrm{ED}_{8}$ NIRS was up to 10 percentage points higher

Table 3 Ruminal degradation parameters and effective degradation of phytate (Ins $\left.P_{6}\right)$ for single feeds $(\mathrm{n}=3$ animals)

\begin{tabular}{|c|c|c|c|c|c|c|c|c|c|c|c|}
\hline & Maize & Wheat & Barley & $\begin{array}{l}\text { Faba } \\
\text { beans }\end{array}$ & Soybeans & $\begin{array}{c}\text { Soybean } \\
\text { meal }\end{array}$ & $\begin{array}{c}\text { Rapeseed } \\
\text { meal }\end{array}$ & $\begin{array}{c}\text { Sunflower } \\
\text { meal }\end{array}$ & DDGS & $\begin{array}{l}\text { Pooled } \\
\text { SEM }\end{array}$ & $P$-values \\
\hline$a$ & $63^{c}$ & $45^{d}$ & $44^{d}$ & $74^{\mathrm{b}}$ & $62^{c}$ & $27^{e}$ & $0^{g}$ & $15^{f}$ & $77^{\mathrm{a}}$ & 0.66 & $<0.001$ \\
\hline$b$ & $37^{e}$ & $55^{d}$ & $56^{d}$ & $26^{f}$ & $38^{e}$ & $73^{c}$ & $100^{\mathrm{a}}$ & $84^{b}$ & $22^{g}$ & 0.71 & $<0.001$ \\
\hline$c$ & $24.9^{\mathrm{ab}}$ & $10.2^{d}$ & $9.4^{d}$ & $14.9^{b c d}$ & $12.2^{\mathrm{cd}}$ & $20.7^{a b c}$ & $7.3^{d}$ & $28.2^{\mathrm{a}}$ & $10.8^{\mathrm{cd}}$ & 3.48 & 0.005 \\
\hline lag & - & - & - & - & - & $3.6^{\mathrm{a}}$ & - & $3.1^{b}$ & - & 0.09 & 0.005 \\
\hline Ins $\mathrm{P}_{6} \mathrm{ED}_{5}$ & $93^{a}$ & $82^{c}$ & $80^{c}$ & $93^{\mathrm{a}}$ & $89^{b}$ & $76^{d}$ & $59^{e}$ & $75^{d}$ & $92^{\mathrm{a}}$ & 0.86 & $<0.001$ \\
\hline $\operatorname{lnsP}_{6} \mathrm{ED}_{8}$ & $90^{a}$ & $76^{c}$ & $74^{c}$ & $91^{a}$ & $85^{b}$ & $66^{d}$ & $48^{e}$ & $65^{d}$ & $89^{a}$ & 1.11 & $<0.001$ \\
\hline
\end{tabular}

$a=$ rapidly degradable fraction (\%); $b=$ potentially degradable fraction $(\%) ; c=$ degradation rate of $b(\% / h) ;$ lag $=$ lag time $(\mathrm{h}) ; \operatorname{lns} \mathrm{P}_{6} \mathrm{ED}=$ effective deg radation (\%) of InsP $\mathrm{P}_{6}$ at a passage rate of $5\left(\mathrm{InsP}_{6} \mathrm{ED}_{5}\right)$ and $8\left(\operatorname{InsP}_{6} \mathrm{ED}_{8}\right) \% / \mathrm{h}$.

DDGS = dried distillers' grains with soluble.

Different superscripts within a row indicate significant differences. 
Haese, Krieg, Grubješić, Feyder and Rodehutscord

Table 4 Ruminal degradation parameters and effective degradation of phytate (InsP $P_{6}$ ) for compound feeds (CF1/2 Mash, CF1/2 Pellet and CF1/2 Calculated, $\mathrm{n}=3$ animals)

\begin{tabular}{|c|c|c|c|c|c|c|c|c|c|c|c|c|c|}
\hline \multirow[b]{2}{*}{ Type } & \multicolumn{3}{|c|}{ CF1 } & \multicolumn{3}{|c|}{ CF2 } & \multirow[b]{2}{*}{ Pooled SEM } & \multirow[b]{2}{*}{ CF1 } & \multirow[b]{2}{*}{ CF2 } & \multirow[b]{2}{*}{ Pooled SEM } & \multicolumn{3}{|c|}{$P$-values } \\
\hline & Mash & Pellet & Calculated & Mash & Pellet & Calculated & & & & & CF $\times$ Type & $\mathrm{CF}$ & Type \\
\hline$a$ & $56^{\mathrm{b}}$ & $71^{\mathrm{a}}$ & $57^{b}$ & $38^{c}$ & $56^{b}$ & $32^{d}$ & 0.95 & & & & $<0.001$ & $<0.001$ & $<0.001$ \\
\hline$b$ & $44^{c}$ & $29^{d}$ & $43^{c}$ & $61^{b}$ & $43^{c}$ & $68^{a}$ & 0.91 & & & & $<0.001$ & $<0.001$ & $<0.001$ \\
\hline$c$ & 10.5 & 11.1 & 12.0 & 18.0 & 20.1 & 14.4 & - & 11.2 & 17.5 & 1.65 & 0.442 & 0.014 & 0.662 \\
\hline lag & - & - & $0.3^{d}$ & $2.5^{b}$ & $3.5^{a}$ & $1.0^{c}$ & 0.18 & & & & $<0.001$ & $<0.001$ & $<0.00$ \\
\hline Ins $\mathrm{P}_{6} \mathrm{ED}_{5}$ & $86^{\mathrm{b}}$ & $91^{\mathrm{a}}$ & $87^{b}$ & $80^{c}$ & $85^{b}$ & $77^{d}$ & 0.73 & & & & 0.022 & $<0.001$ & $<0.00$ \\
\hline Ins $\mathrm{P}_{6} \mathrm{ED}_{8}$ & $81^{b}$ & $88^{a}$ & $82^{b}$ & $72^{c}$ & $80^{b}$ & $69^{d}$ & 0.87 & & & & 0.030 & $<0.001$ & $<0.00$ \\
\hline
\end{tabular}

$a=$ rapidly degradable fraction (\%); $b=$ potentially degradable fraction (\%); $c=$ degradation rate of $b(\% / h)$; lag = lag time $(\mathrm{h}) ; \operatorname{lns} \mathrm{P}_{6} \mathrm{ED}=$ effective degradation $(\%)$ of InsP $\mathrm{P}_{6}$ at a passage rate of $5\left(\mathrm{InsP}_{6} \mathrm{ED}_{5}\right)$ and $8\left(\mathrm{InsP}_{6} \mathrm{ED}_{8}\right) \% / \mathrm{h}$.

CF1 = compound feed 1 (containing 10\% maize, $46 \%$ barley, $16 \%$ faba beans, $18 \%$ soybeans, $5 \%$ soybean meal, $5 \%$ dried distillers' grains with solubles (DDGS) on DM basis); CF2 = compound feed 2 (containing $32 \%$ maize, $12 \%$ wheat, $16 \%$ faba beans, $8 \%$ soybean meal, $17 \%$ rapeseed meal, $10 \%$ sunflower meal, $5 \%$ DDGS on DM basis).

CF Calculated $=$ ruminal degradation parameters and effective degradation of $\mathrm{InsP}_{6}$ calculated from single feeds.

Different superscripts within a row indicate significant differences.
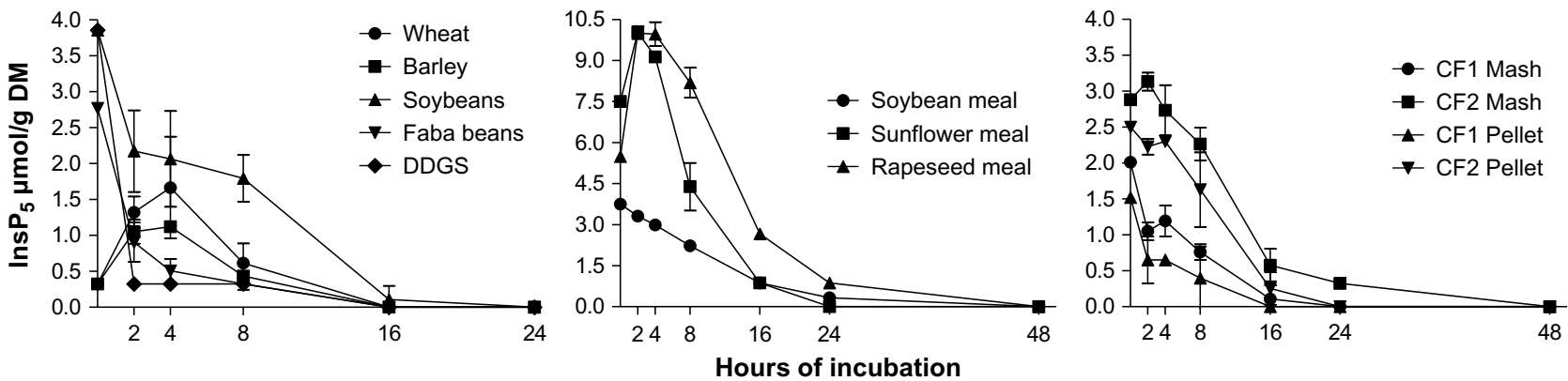

Figure 1 Concentrations of myo-inositol pentakisphosphate $\left(\mathrm{InsP}_{5} ; \mu \mathrm{mol} / \mathrm{g} \mathrm{DM}\right)$ in the bag residues of in situ incubated single and compound feeds at different incubation times ( $n=3$ animals; DDGS = dried distillers' grains with solubles; CF1 = compound feed 1 (containing 10\% maize, 46\% barley, 16\% faba beans, $18 \%$ soybeans, $5 \%$ soybean meal, $5 \%$ DDGS on DM basis); CF2 = compound feed 2 (containing $32 \%$ maize, $12 \%$ wheat, $16 \%$ faba beans, $8 \%$ soybean meal, $17 \%$ rapeseed meal, $10 \%$ sunflower meal, $5 \%$ DDGS on DM basis).

Table 5 Performance of different calibrations for estimating the phytate $\left(I n s P_{6}\right)$ concentration of single feeds, compound feeds and their bag residues after ruminal in situ incubation; cross-validation groups: 5

\begin{tabular}{|c|c|c|c|c|c|c|c|c|c|c|c|}
\hline \multirow[b]{2}{*}{$\begin{array}{l}\text { Data } \\
\text { set }\end{array}$} & \multicolumn{2}{|c|}{ Settings } & \multicolumn{4}{|c|}{ Calibration } & \multicolumn{5}{|c|}{ Validation } \\
\hline & $\begin{array}{l}\text { Wavelength } \\
\quad(\mathrm{nm})\end{array}$ & $D, G, S$ & Factors & $\begin{array}{c}\text { Samples } \\
\text { Available/ } \\
\text { used }\end{array}$ & $\begin{array}{c}\text { SEC } \\
(\mu \mathrm{mol} / \mathrm{g})\end{array}$ & $R^{2}$ & $\begin{array}{c}\text { SEP } \\
(\mu \mathrm{mol} / \mathrm{g})\end{array}$ & $R^{2}$ & $\begin{array}{c}\text { Bias } \\
(\mu \mathrm{mol} / \mathrm{g})\end{array}$ & Slope & $\begin{array}{l}\text { Intercept } \\
(\mu \mathrm{mol} / \mathrm{g})\end{array}$ \\
\hline (1) & 1250 to 2450 & $1,8,8$ & 15 & $127 / 127$ & 3.6 & 0.95 & 5.3 & 0.90 & -0.76 & 1.04 & -1.55 \\
\hline (2) & 1250 to 2450 & $1,8,8$ & 15 & $259 / 259$ & 3.9 & 0.94 & 4.5 & 0.93 & -0.43 & 1.02 & -0.88 \\
\hline (3) & 1250 to 2450 & $1,8,8$ & 15 & $229 / 229$ & 4.0 & 0.94 & 5.1 & 0.92 & -0.61 & 1.03 & -1.23 \\
\hline (4) & 680 to 2500 & $1,8,8$ & 5 & $95 / 87$ & 1.5 & 0.92 & 4.2 & 0.66 & $<0.01$ & 1.00 & $<0.01$ \\
\hline (5) & 1250 to 2450 & $1,8,8$ & 15 & $156 / 156$ & 3.2 & 0.97 & 4.6 & 0.95 & -0.61 & 1.03 & -1.24 \\
\hline (6) & 1250 to 2450 & $1,8,8$ & 15 & $220 / 220$ & 3.7 & 0.95 & 4.2 & 0.94 & -0.32 & 1.02 & -0.64 \\
\hline (7) & 1250 to 2450 & $1,8,8$ & 15 & $117 / 117$ & 3.3 & 0.97 & 3.9 & 0.97 & -1.01 & 1.04 & -2.06 \\
\hline
\end{tabular}

D,G,S = Derivation, Gap, Smooth; $R^{2}=$ squared correlation coefficient: $S E C=$ Standard Error of Calibration; SEP = Standard Error of Prediction; data set 1: all values for feeds and bag residues of the present study; data set 2: all values for feeds and bag residues of the present study and the additional studies (Seifried et al., 2016 and 2017; Haese et al., 2017c, Krieg et al., 2017); data set 3: data set 2, but excluding all values for rye and triticale; data set 4: only values for feeds and bag residues from grain samples of the present study and the additional studies; data set 5: data set 2, but excluding all values for grain samples; data set 6 : data set 2, but excluding all values for compound feeds; data set 7: data set 2, but excluding all values for compound feeds and grain samples. 
(a)

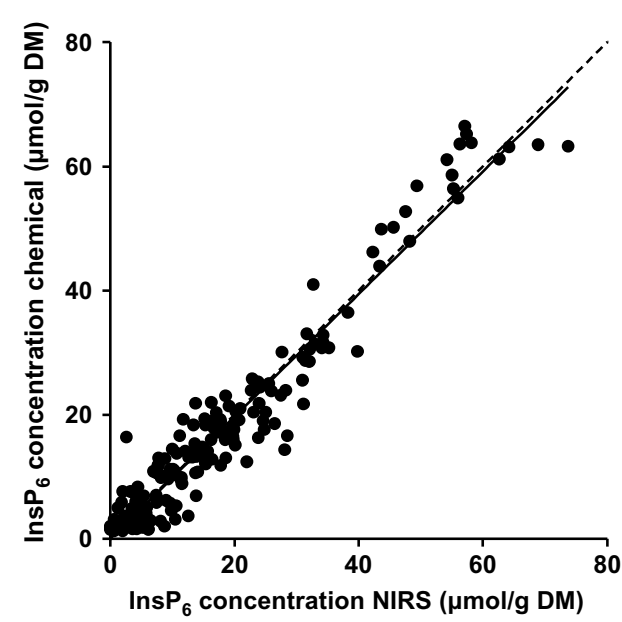

(b)

Data set 1

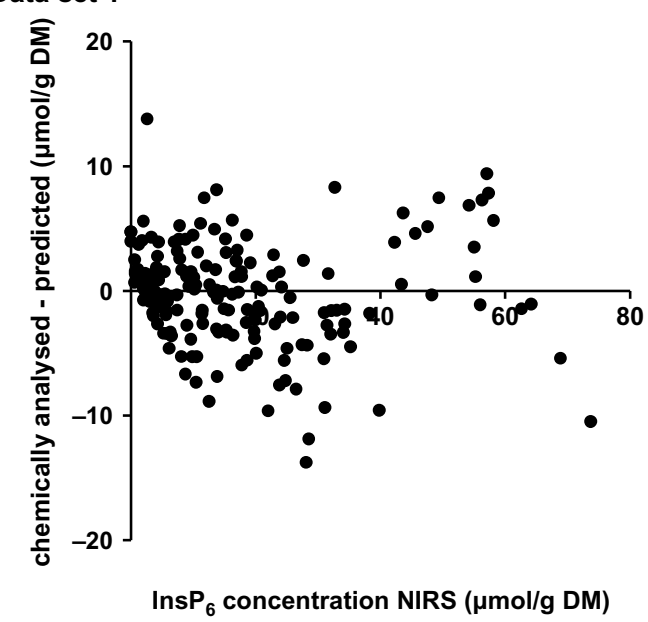

Data set 2
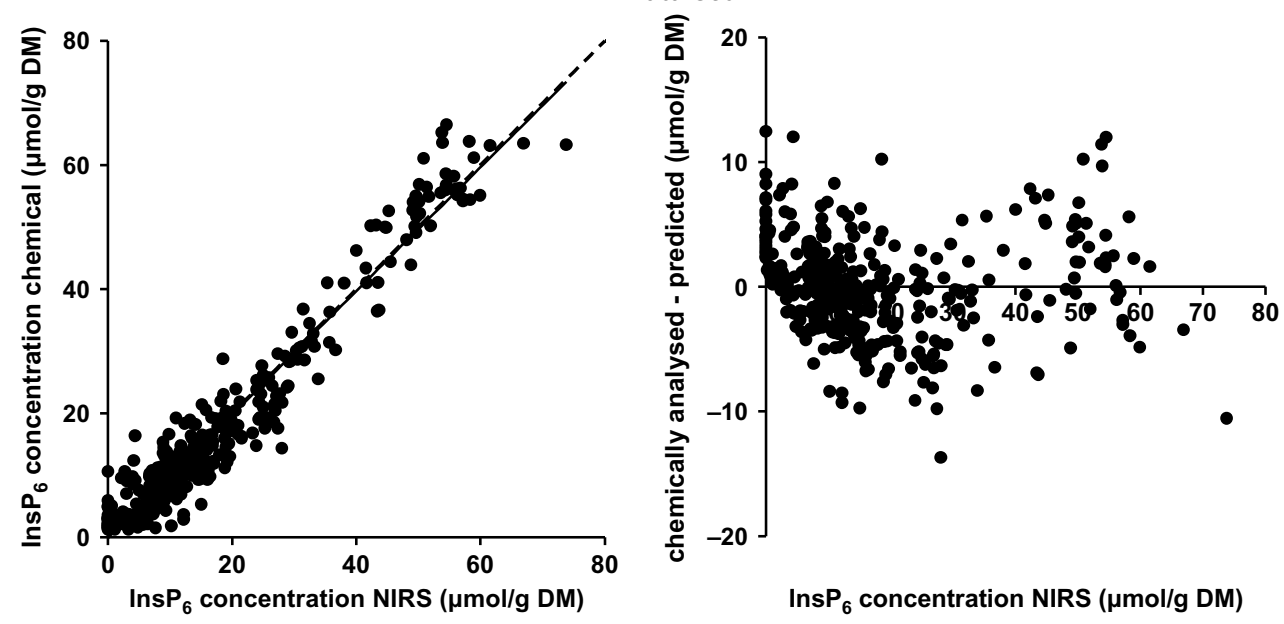

Data set 7
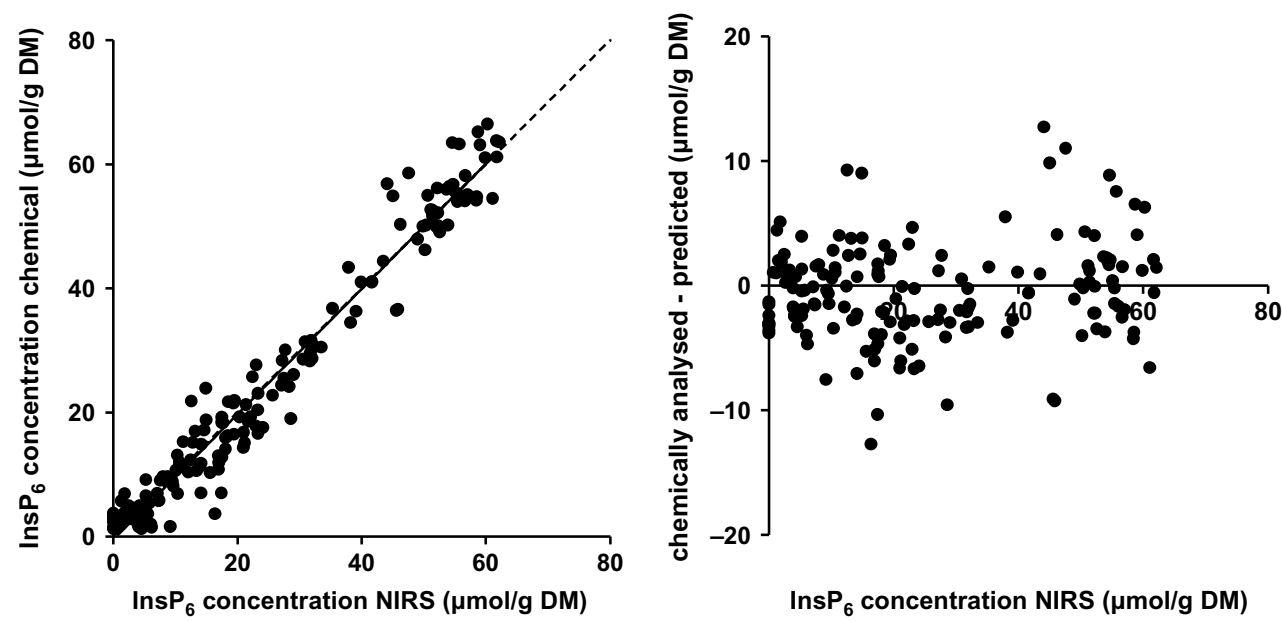

Figure 2 (a) Phytate (Ins $\mathrm{P}_{6}$ ) concentrations (predicted with near-infrared spectroscopy (NIRS) vs. chemically analysed) in samples from in situ studies based on data sets 1, 2 and 7, the corresponding regression line (solid line) and the bisectrix (dashed line). (b) Difference between NIRS predicted and chemically analysed Ins $\mathrm{P}_{6}$ concentrations in samples of in situ studies. Negative values were treated as zero.

compared to $\operatorname{InsP}_{6} \mathrm{ED}_{8} \mathrm{HPIC}$. On the other hand, $\operatorname{Ins}_{6} \mathrm{ED}_{8}$ NIRS for maize, SBM and SFM was up to 16 percentage points lower compared to Ins $\mathrm{P}_{6} \mathrm{ED}_{8} \mathrm{HPIC}$. For the other feeds (faba beans, soybeans, RSM, DDGS, CF1 Pellet, CF2 Mash and CF2 Pellet), InsP ${ }_{6}$ ED NIRS and InsP $\mathrm{P}_{6} \mathrm{ED}$ HPIC did not differ significantly. 


\section{Discussion}

Phytate degradation from single feeds

The wide variation in $\mathrm{InSP}_{6} \mathrm{ED}$ between the examined feeds proves the necessity to evaluate the ruminal degradation of InsP $\mathrm{P}_{6}$ individually for single feeds. The results showed that even when feeds are categorised in legume seeds (faba beans, soybeans), cereals (maize, wheat, barley) and oilseed meals (SFM, SBM, RSM), InsP 6 ED varies widely within these categories. For unprocessed feeds, the extent of ruminal Ins $\mathrm{P}_{6}$ degradation seems to be influenced mainly by localisation and binding of InsP $\mathrm{P}_{6}$ in the seeds (Haese et al., 2017a and 2017b). However, the effects of genotype and harvest year on $\mathrm{Ins}_{6}$ degradation of legume seeds and cereal grains have not yet been studied. As variation of ruminal CP degradation between barley $\left(\mathrm{ED}_{8}: 69 \%\right.$ to $80 \%$; Krieg et al., $2018 \mathrm{~b})$ and wheat $\left(\mathrm{ED}_{8}: 72 \%\right.$ to $80 \%$; Seifried et al., 2017) genotypes has been observed, this might also apply to ruminal Ins $\mathrm{P}_{6}$ degradation. In a previous study, we examined the correlation between $\mathrm{CP}$ and $\mathrm{InSP}_{6}$ disappearance for different feeds and found high coefficients of determination for the linear regressions $\left(R^{2} \geq 0.93\right.$ for oilseed meals, $R^{2}=0.83$ for wheat; Haese et al., 2017b). Therefore, factors influencing ruminal $\mathrm{CP}$ degradation might also affect ruminal InsP $_{6}$ degradation.

For processed feeds such as oilseed meals, processing conditions seem to have a major influence on the extent of ruminal $\operatorname{InS}_{6}$ degradation and might explain the relatively low InsP $\mathrm{P}_{6} \mathrm{ED}$ of SBM and RSM compared to other studies. In the studies of Konishi et al. (1999) and Park et al. (1999), Ins $\mathrm{P}_{6} \mathrm{ED}_{8}$ was $59 \%$ for $\mathrm{RSM}$ and $74 \%$ for $\mathrm{SBM}$, while in the present study, $\operatorname{Ins}_{6} \mathrm{ED}_{8}$ was only $48 \%$ for $\mathrm{RSM}$ and $66 \%$ for SBM. Heat treatment seems to have a major influence on InsP $\mathrm{P}_{6} \mathrm{ED}$, as additional heating of meals for $3 \mathrm{~h}$ at different temperatures $\left(133^{\circ} \mathrm{C}, 143^{\circ} \mathrm{C}, 153^{\circ} \mathrm{C}\right)$ reduced InsP $\mathrm{EDD}_{8}$ for both RSM $(46 \%, 42 \%, 14 \%)$ and SBM $(65 \%$, $57 \%$, 45\%; Konishi et al. (1999)). Steingass et al. (2013) and Broderick et al. (2016) found considerable variation of ruminal degradability of CP in RSM from different oil mills and explained these observations with different heating procedures during toasting. Because disappearance of $\mathrm{CP}$ and Ins $\mathrm{P}_{6}$ is correlated in oilseed meals (Haese et al., 2017b), it is likely that ruminal $\operatorname{InsP}_{6}$ degradation in RSM and SBM also depends on the production process and thus differs between meals from different processing plants. The same might apply to SFM where, to the best of the authors' knowledge, data on ruminal Ins $\mathrm{P}_{6}$ degradation have not yet been published.

As no accumulation of InsP $\mathrm{P}_{3-5}$ was observed for any incubated feed, it can be assumed that $\operatorname{InsP}_{6}$ is completely dephosphorylated once this process has begun on an $\operatorname{InsP}_{6}$ molecule. For poultry, it has been shown that, even when phytase is supplemented to the feed, $\operatorname{Ins}_{6}$ is not completely dephosphorylated in the precaecal part of the digestive tract (Sommerfeld et al., 2018). In ruminants, however, the in vitro study of Brask-Pedersen et al. (2011) as well as the in situ study of Haese et al. (2017b) suggested that the crucial step 
in $\mathrm{Ins}_{6}$ degradation is the cleavage of the first phosphate group and hydrolysis of InsP $\mathrm{P}_{5}$ and lower InsPs follows soon after. This is consistent with the results of the present study and can probably be assumed for all feedstuffs as a quite broad range of feeds was examined. Still little is known about phytase-producing bacteria and their specific phytases, but Nakashima et al. (2007) found two different phytase sequences in the rumen bacterium Selenomonas lacticifex and suggested that in this bacterium multiple phytate degrading enzymes are present. Furthermore, Li et al. (2014) found that phytase-producing microorganisms did not constantly secrete functional phytases, when rumen samples gained at different times after feeding were analysed. This indicates that in the rumen various phytases are available at any time leading to complete hydrolysis of $\operatorname{InsP}_{6}$, whereas in nonruminants, where diets are usually supplemented with only one specific phytase, lower InsPs do accumulate.

\section{Additivity of phytate degradation of compound feeds and pelleting effect}

Compound feeds are often pelleted, hence it is of practical value if InsP $P_{6} E D$ can be calculated from that of single feeds. Calculated Ins $\mathrm{P}_{6} \mathrm{ED}$ underestimated observed $\operatorname{Ins}_{6} \mathrm{ED}$ of both CF1 Pellet (InsP $\mathrm{ED}_{5}: 4$, InsP $\mathrm{ED}_{8}: 6$ percentage points) and CF2 Pellet (InsP $\mathrm{E}_{6} \mathrm{ED}_{5}: 8$, Ins $\mathrm{P}_{6} \mathrm{ED}_{8}: 11$ percentage points). This suggests that, at present, InsP $\mathrm{P}_{6} \mathrm{ED}$ of $\mathrm{CF}$ cannot be calculated reliably with sufficient precision from values of single feeds. As the difference between calculated and observed values of InsP $\mathrm{P}_{6} \mathrm{ED}$ was smaller for $\mathrm{CF} 1$, the precision of the calculation could depend on the single feeds used. So far, CF are mainly used to supply energy and $\mathrm{CP}$, and their contribution to $\mathrm{P}$ supply has not yet been of major interest. However, depending on the constituent single feeds its contribution can be relevant, and gaining an estimate of the availability of this $P$ source is an improvement towards precise calculation of diets. Thus, further research is required on this topic as we examined only two different $C F$ in the present study.

Both CF1 Pellet and CF2 Pellet showed higher $\operatorname{InsP}_{6} E D$ values compared to the respective Mash (CF1: $\operatorname{InsP}_{6} \mathrm{ED}_{5}: 5$, InsP $\mathrm{ED}_{6}$ : 7 percentage points; $\mathrm{CF} 2$ : InsP $\mathrm{E}_{6} \mathrm{ED}_{5}$ : 5 ; InsP $\mathrm{F}_{6} \mathrm{ED}_{8}$ : 8 percentage points). This effect was also observed for effective degradation of CP in CF1 and CF2 (Grubješić et al., 2019). As degradation rate $c$ was not affected by pelleting, this effect can probably be ascribed to the increase of fraction a after pelleting (CF1: 15, CF2: 18 percentage points). A higher proportion of finer particles was measured after pelleting of CF1 and CF2 (Grubješić et al., 2019), and it can be concluded that the increased $\operatorname{InsP}_{6} E D$ in pelleted feeds derived from fine particles which were prone to leave the bag undegraded and thus increased fraction $a$. As mentioned before, heat treatment at high temperatures usually impairs ruminal Ins $\mathrm{P}_{6}$ degradation. Pelleting proceeded at a temperature of $50^{\circ} \mathrm{C}$ to $60^{\circ} \mathrm{C}$, and the exit temperature of the pellets was $80^{\circ} \mathrm{C}$ to $90^{\circ} \mathrm{C}$. Either this temperature was not sufficient to facilitate any structural changes decreasing $\operatorname{lns}_{6}$ degradation or the changes in particle size distribution covered this effect.

\section{Prediction of phytate concentrations using near-infrared spectroscopy}

The performance of the calibration based on data set 7 yielded the highest $R^{2}$ in the validation step and the lowest SEP of all calibrations. Thus, the difference between the chemically analysed and NIRS predicted Ins $\mathrm{P}_{6}$ concentrations were overall lower for data set 7 than for the other calibrations (Figure 2). However, the bias and intercept were higher for data set 7 calibrations than for the other sets. When regressions were calculated between the error of $\operatorname{Ins}_{6}$ predictions and the predicted $\operatorname{Ins}_{6}$ concentrations, slopes were not significant in any case. This implies that the error of the prediction did not depend on the $\operatorname{Ins}_{6}$ concentration of the sample. This, in turn, means that the prediction of $\operatorname{Ins}_{6}$ concentrations is possible with similar accuracy for feed samples and bag residues, where $\mathrm{InsP}_{6}$ concentrations are distinctly lower due to ruminal incubation.

Overall, the performance of calibrations in the present study was not as good as the performance of calibrations for the prediction of CP concentrations in similar samples (Krieg et al., 2018a). For most of the data sets, the wavelength segment of 1250 to $2450 \mathrm{~nm}$ was selected for prediction of $\mathrm{CP}$ and $\operatorname{InsP}_{6}$ concentration. The aforementioned correlation between $\mathrm{CP}$ and $\mathrm{Ins}_{6}$ concentration in different feeds (Haese et al., 2017b) and the preference for the same wavelength segments support the theory of $\operatorname{InsP}_{6}$ being indirectly predicted from CP. Since Ins $\mathrm{P}_{6}$ and $\mathrm{CP}$ concentrations are correlated but do not change directly proportional, this theory would also explain the lower performance of InsP $_{6}$ calibrations compared to the calibrations for predicting CP concentration.

The improvement of the performance of the calibrations by exclusion of cereal grains and CF suggests that strong matrix effects exist between cereal grain samples and protein feeds. No clear separation of spectra from cereal grain samples and their incubation residues from the other samples was visible (principal component analysis plot, data not shown, MATLAB, Fathom Toolbox; Jones (2014)). However, the decrease in the SEP and the increase in the $R^{2}$ upon exclusion of grain samples suggest that separate calibrations for cereal grains and protein-rich feeds should be further worked on. Assumedly, the matrix effects occur due to different interactions between $\operatorname{Ins}_{6}$ and $C P$ in cereal grains and protein feeds which result in differing degradation kinetics of $C P$ and Ins $P_{6}$. This probably leads to changes in the relations between $\operatorname{Ins}_{6}$ and $\mathrm{CP}$ concentrations of feeds and bag residues which might affect protein-rich feeds to a different extent than cereal grains. Together with the previously assumed indirect prediction of $\operatorname{Ins}_{6}$ by $\mathrm{CP}$, this could lead to a less favourable performance of global calibrations. This theory is supported by the relatively homogenous distribution of the samples in the PCA plot. A separation of grain samples based on the error of the prediction could be expected based on the comparison of the $\operatorname{Ins}_{6} \mathrm{ED}$ values, but was not given for any of the calibrations (Figure 2). The comparison of InsP $\mathrm{P}_{6} \mathrm{ED}$ NIRS with InsP $\mathrm{P}_{6} \mathrm{ED}$ HPIC also indicates that the NIRS prediction of $\operatorname{Ins}_{6}$ concentrations is not 
yet sufficiently accurate. While no differences between InsP $P_{6} E D$ NIRS and InsP $P_{6}$ ED HPIC were observed for some feeds, Ins $P_{6} E D$ NIRS was considerably lower (e.g. 16 percentage points for SFM) or higher (e.g. 10 percentage points for wheat) for other feeds. This underlines the need for more data to develop suitable calibrations.

The authors are not aware of any study that reported calibrations to predict $\mathrm{InSP}_{6}$ concentrations in ruminally incubated samples. However, calibrations do exist to predict InsP ${ }_{6}-\mathrm{P}$ concentration in poultry feeds (Tahir et al., 2012; Aureli et al., 2017). Values of the present study expressed as $\operatorname{lns}_{6}-P$ ranged from 0.23 to $12.12 \mathrm{~g} / \mathrm{kg}$, which is in a similar range as the values of Tahir et al. (2012) and Aureli et al. (2017). In the study of Tahir et al. (2012), the $R^{2}$ of the validation step ranged from 0.67 (maize) to 0.94 (wheat shorts) and the SEP from $0.09 \mathrm{~g} / \mathrm{kg}$ (SBM) to $0.23 \mathrm{~g} / \mathrm{kg}$ (maize, DDGS). Recalculation of the SEP in the present study to $\mathrm{g} / \mathrm{kg}$ InsP $\mathrm{P}_{6}-\mathrm{P}$ resulted in slightly higher SEP values between 0.7 and $1.0 \mathrm{~g} / \mathrm{kg}$. Calibrations of Aureli et al. (2017) were based on a slightly bigger range of reference $\operatorname{Ins}_{6}-\mathrm{P}$ concentrations $\left(0.2\right.$ to $14.1 \mathrm{~g} / \mathrm{kg}$ ) and showed a comparable $R^{2}(0.94)$ and SEP $(0.67 \mathrm{~g} / \mathrm{kg})$ than most of the calibrations of the present study. The slightly higher SEP values observed here are probably due to the more heterogeneous sample material (feeds and bag residues after different incubation times) compared to calibrations comprising only feedstuffs. Besides the establishment of local calibrations, the usage of other chemometric techniques than PLS might help to improve the accuracy of the prediction. First trials with data of the present study utilising artificial neural networks instead of PLS to predict InsP $\mathrm{P}_{6}$ concentrations delivered promising results and should be further investigated. Overall, the calibrations that were established in the present study demonstrate that Ins $\mathrm{P}_{6}$ can be predicted by NIRS in incubated samples of in situ studies as well as in feeds. However, the results also show that the used database needs to be expanded to achieve sufficient performance of the calibrations for the use in in situ studies.

The results of the present study indicate that the availability of Ins $\mathrm{P}_{6}-\mathrm{P}$ should be evaluated individually for feeds. However, to broaden the data base on ruminal $\operatorname{Ins}_{6}$ degradation of different feeds establishing a fast and easy method for analysis of $\operatorname{InsP}_{6}$ is a decisive factor. Predicting $\operatorname{Ins}_{6}$ concentrations in feeds and bag residues using NIRS proved to have the potential to simplify the analytical step of $\operatorname{InsP}_{6}$ in future in situ studies.

\section{Acknowledgements}

Doctoral scholarships of the Faculty of Agricultural Sciences of the University of Hohenheim and the H. Wilhelm Schaumann Stiftung for Goran Grubješić are gratefully acknowledged. The authors are grateful to Raiffeisen Kraftfutterwerk (RKW) Kehl for providing single feeds samples and facilities for mixing and pelleting of $\mathrm{CF}$.

E. Haese 0000-0001-7795-1750

J. Krieg 0000-0002-6614-1442

G. Grubješić 0000-0002-5007-6973

M. Rodehutscord 0000-0003-3156-7889

\section{Declaration of interest}

The authors have no conflicts of interest to declare.

\section{Ethics statement}

The conduction of the study was in accordance with the German animal welfare regulations. Housing, diets and incubation procedure were approved by the Regierungspräsidium Stuttgart (Germany, approval code V319/14 TE).

\section{Software and data repository resources}

None of the data were deposited in an official repository.

\section{References}

Aureli R, Ueberschlag Q, Klein F, Noël C and Guggenbuhl P 2017. Use of near infrared reflectance spectroscopy to predict phytate phosphorus, total phosphorus, and crude protein of common poultry feed ingredients. Poultry Science 96, 160-168.

Bellon-Maurel V, Fernandez-Ahumada E, Palagos B, Roger JM and McBratney A 2010. Critical review of chemometric indicators commonly used for assessing the quality of the prediction of soil attributes by NIR spectroscopy. Trends in Analytical Chemistry 29, 1073-1081.

Blaabjerg K, Hansen-Møller J and Poulsen HD 2010. High-performance ion chromatography method for separation and quantification of inositol phosphates in diets and digesta. Journal of Chromatography B 878, 347-354.

Brask-Pedersen DN, Glitsø LV, Skov LK, Lund P and Sehested J 2011. Effect of exogenous phytase on feed inositol phosphate hydrolysis in an in vitro rumen fluid buffer system. Journal of Dairy Science 94, 951-959.

Broderick GA, Colombini S, Costa S, Karsli MA and Faciola AP 2016. Chemical and ruminal in vitro evaluation of Canadian canola meals produced over 4 years. Journal of Dairy Science 99, 7956-7970.

Desmit X, Thieu V, Billen G, Campuzano F, Dulière V, Garnier J, Lassaletta L, Ménesguen A, Neves R, Pinto L, Silvestre M, Sobrinho JL and Lacroix G 2018. Reducing marine eutrophication may require a paradigmatic change. Science of the Total Environment 635, 1444-1466.

Grubješić G, Titze N, Krieg J and Rodehutscord M 2019. Determination of in situ ruminal crude protein and starch degradation values of compound feeds from single feeds. Archives of Animal Nutrition 73, 414-429.

Haese E, Krieg J, Seifried N, Schollenberger M, Steingass H and Rodehutscord M 2017c. Ruminaler Abbau von Rohprotein und Phytat aus unterschiedlich behandelten Rapsprodukten. In Kurzfassungsband des 129. VDLUFA-Kongresses, p. 114. VDLUFA-Verlag, Darmstadt, Germany.

Haese E, Lengowski M, Gräter E, Föll A, Möhring J, Steingass $H$, Schollenberger $M$ and Rodehutscord M 2017a. Ruminal phytate degradation of maize grain and rapeseed meal in vitro and as affected by phytate content in donor animal diets and inorganic phosphorus in the buffer. Journal of Animal Physiology and Animal Nutrition 101, 868-880.

Haese E, Möhring J, Steingass H, Schollenberger M and Rodehutscord M 2017b. Effect of dietary mineral phosphorus and phytate on in situ ruminal phytate disappearance from different concentrates in dairy cows. Journal of Dairy Science 100, 3672-3684.

Haese E, Müller K, Steingass H, Schollenberger M and Rodehutscord M 2014. Effects of mineral and rapeseed phosphorus supplementation on phytate degradation in dairy cows. Archives of Animal Nutrition 68, 478-491.

Jones DL 2014. Fathom Toolbox for MATLAB: software for multivariate ecological and oceanographic data analysis. College of Marine Science, University of South Florida, St. Petersburg, FL, USA. Retrieved from https://www.marine. usf.edu/research/matlab-resources/

Kincaid RL, Garikipati DK, Nennich TD and Harrison JH 2005. Effect of grain source and exogenous phytase on phosphorus digestibility in dairy cows. Journal of Dairy Science 88, 2893-2902.

Konishi C, Matsui T, Park W, Yano H and Yano F 1999. Heat treatment of soybean meal and rapeseed meal suppresses rumen degradation of phytate phosphorus in sheep. Animal Feed Science and Technology 80, 115-122. 
Krieg J, Koenzen E, Seifried N, Steingass H, Schenkel H and Rodehutscord M 2018a. Prediction of CP and starch concentrations in ruminal in situ studies and ruminal degradation of cereal grains using NIRS. Animal 12, 472-480.

Krieg J, Seifried N, Steingass H and Rodehutscord M 2017. In situ and in vitro ruminal starch degradation of grains from different rye, triticale and barley genotypes. Animal 11, 1745-1753.

Krieg J, Seifried N, Steingass H and Rodehutscord M 2018b. In situ and in vitro evaluation of crude protein degradation and utilisable crude protein content of barley, rye and triticale grains for ruminants. Journal of Animal Physiology and Animal Nutrition 102, 452-461.

Li Z, Huang $H$, Zhao $H$, Meng $K$, Zhao J, Shi $P$, Yang $P$, Luo $H$, Wang $Y$ and Yao B 2014. Genetic diversity and expression profiles of cysteine phytases in the sheep rumen during a feeding cycle. Letters in Applied Microbiology 59 615-620.

McDonald I 1981. A revised model for the estimation of protein degradability in the rumen. Journal of Agricultural Science 96, 251-252.

Morse D, Head HH and Wilcox CJ 1992. Disappearance of phosphorus in phytate from concentrates in vitro and from rations fed to lactating dairy cows. Journal of Dairy Science 75, 1979-1986.

Nakashima BA, McAllister TA, Sharma R and Selinger LB 2007. Diversity of phytases in the rumen. Microbial Ecology 53, 82-88.

Orskov ER and McDonald I 1979. The estimation of protein degradability in the rumen from incubation measurements weighted according to rate of passage. Journal of Agricultural Science 92, 499-503.

Park WY, Matsui T, Konishi C, Sung-Won K, Yano F and Yano H 1999 Formaldehyde treatment suppresses ruminal degradation of phytate in soyabean meal and rapeseed meal. British Journal of Nutrition 81, 467-471.

Ray PP, Jarrett J and Knowlton KF 2013. Effect of dietary phytate on phosphorus digestibility in dairy cows. Journal of Dairy Science 96, 1156-1163.

Seifried N, Steingass H, Hoffmann N and Rodehutscord M 2017. In situ starch and crude protein degradation in the rumen and in vitro gas production kinetics of wheat genotypes. Journal of Animal Physiology and Animal Nutrition 101 779-790.
Seifried N, Steingass H, Schipprack W and Rodehutscord M 2016. Variation in ruminal in situ degradation of crude protein and starch from maize grains compared to in vitro gas production kinetics and physical and chemical characteristics. Archives of Animal Nutrition 70, 333-349.

Sommerfeld V, Schollenberger M, Kühn I and Rodehutscord M 2018. Interactive effects of phosphorus, calcium, and phytase supplements on products of phytate degradation in the digestive tract of broiler chickens. Poultry Science 97, 1177-1188.

Steingass H, Kneer G, Wischer G and Rodehutscord M 2013. Variation of in situ rumen degradation of crude protein and amino acids and in vitro digestibility of undegraded feed protein in rapeseed meals. Animal 7, 1119-1127.

Tahir M, Shim MY, Ward NE, Westerhaus MO and Pesti GM 2012. Evaluation of near-infrared reflectance spectroscopy (NIRS) techniques for total and phytate phosphorus of common poultry feed ingredients. Poultry Science 91, 2540-2547.

Verband Deutscher Landwirtschaftlicher Untersuchungs- und Forschungsanstalten 2007. Handbuch der Landwirtschaftlichen Versuchs- und Untersuchungsmethodik Bd. III: Die chemische Untersuchung von Futtermitteln. VDLUFA-Verlag, Darmstadt, Germany.

Wu Z, Satter LD, Blohowiak AJ, Stauffacher RH and Wilson JH 2001. Milk production, estimated phosphorus excretion, and bone characteristics of dairy cows fed different amounts of phosphorus for two or three years. Journal of Dairy Science 84, 1738-1748.

Wulf $\mathrm{M}$ and Südekum KH 2005. Effects of chemically treated soybeans and expeller rapeseed meal on in vivo and in situ crude fat and crude protein disappearance from the rumen. Animal Feed Science and Technology 118, 215-227.

Yanke LJ, Bae HD, Selinger LB and Cheng KJ 1998. Phytase activity of anaerobic ruminal bacteria. Microbiology 144, 1565-1573.

Zeller E, Schollenberger M, Kühn I and Rodehutscord M 2015. Hydrolysis of phytate and formation of inositol phosphate isomers without or with supplemented phytases in different segments of the digestive tract of broilers. Journal of Nutritional Science 4, e1. doi: 10.1017/jns.2014.62

Zhao R, Xu X, Li J, Li C, Chen J, Liu Y and Zhu S 2017. Rapid determination of phytic acid content in cottonseed meal via near infrared spectroscopy. Journal of Near Infrared Spectroscopy 25, 188-195. 